\title{
Measuring mass: Variation among 3,161 species of Canadian Coleoptera and the prospects of a mass registry for all insects
}

\author{
Jingchan Hu ${ }^{1,2}$, Mikko Pentinsaari ${ }^{\text {Corresp., }}$, Paul DN Hebert ${ }^{1,2}$ \\ ${ }^{1}$ Centre for Biodiversity Genomics, University of Guelph, Guelph, Ontario, Canada \\ 2 Department of Integrative Biology, University of Guelph, Guelph, Ontario, Canada \\ Corresponding Author: Mikko Pentinsaari \\ Email address: mpentins@uoguelph.ca
}

Although biomass values are critical for diverse ecological and evolutionary analyses, they are unavailable for most insect species. Museum specimens have the potential to address this gap, but the variation introduced by sampling and preservation methods is uncertain. This study quantifies species-level variation in the body mass of Canadian Coleoptera based on the analysis of 3,744 specimens representing 3,161 Barcode Index Number (BIN) clusters. Employing the BIN system as a proxy for species allows the inclusion of groups where the taxonomic impediment prevents the assignment of specimens to a Linnaean species. By validating the reproducibility of measurements and evaluating the error introduced by operational complexities such as curatorial practice and the loss of body parts, this study demonstrates that museum specimens can speed the assembly of a mass registry. The results further indicate that congeneric species of Coleoptera generally have limited variation in mass, so a genus-level identification allows prediction of the body mass of species that have not been weighed or measured. Building on the present results, the construction of a mass registry for all insects is feasible. 
1 Measuring Mass: Variation among 3,161 species of

2 Canadian Coleoptera and the prospects of a mass

3 registry for all insects

4

5

6

7

8

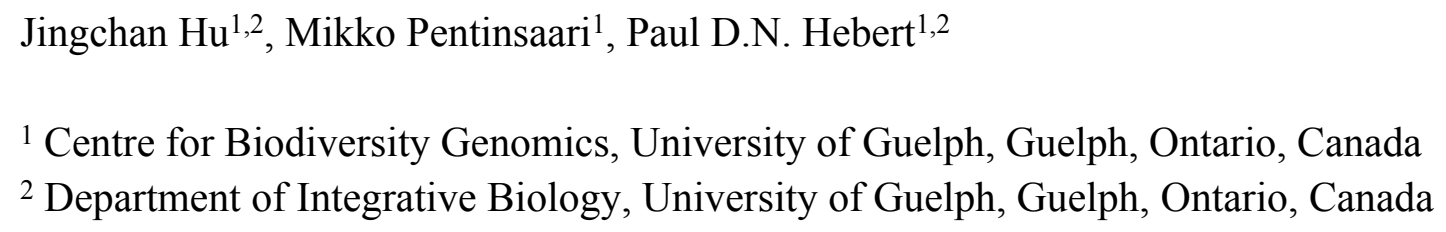

\section{Abstract}

Although biomass values are critical for diverse ecological and evolutionary analyses, they are unavailable for most insect species. Museum specimens have the potential to address this gap, but the variation introduced by sampling and preservation methods is uncertain. This study quantifies species-level variation in the body mass of Canadian Coleoptera based on the analysis of 3,744 specimens representing 3,161 Barcode Index Number (BIN) clusters. Employing the BIN system as a proxy for species allows the inclusion of groups where the taxonomic impediment prevents the assignment of specimens to a Linnaean species. By validating the reproducibility of measurements and evaluating the error introduced by operational complexities such as curatorial practice and the loss of body parts, this study demonstrates that museum specimens can speed the assembly of a mass registry. The results further indicate that congeneric species of Coleoptera generally have limited variation in mass, so a genus-level identification allows prediction of the body mass of species that have not been weighed or measured. Building on the present results, the construction of a mass registry for all insects is feasible.

\section{Introduction}

Body mass is a key property of organisms which impacts factors ranging from metabolic rate to community structure, foraging behavior, and predator-prey dynamics (Peters, 1986; Chown \& Gaston, 2010; Smith et al., 2016). Comprehensive body mass registries are available for mammals (Jones et al., 2009), fishes (Froese \& Pauly, 2021), and birds (Dunning, 2008), but 
40 similar information is lacking for insects despite their abundance and ecological importance.

41 Three characteristics of insects have impeded its assembly: 1) high species diversity, 2) variable

42 curatorial practices, and 3) small size requires access to precision balances (Braun et al., 2009;

43 Chown \& Gaston, 2010; Gilbert, 2011; Knapp, 2012). These barriers to direct mass

44 measurements have led many studies to employ estimates derived from body length, even for

45 groups with very divergent body plans (Rogers, Hinds \& Buschbom, 1976). Despite its lack of

46 precision (Gowing \& Recher, 1984; Johnston \& Cunjak, 1999), this approach has been widely

47 applied due to its simplicity (Ulrich, 2007; Greve et al., 2018; Richard, Tallamy \& Mitchell,

48 2019). Aside from the fact that direct measurements of body mass for arthropods are uncommon,

49 existing data are difficult to access because there is no structured data repository (Chown \&

50 Gaston, 2010).

51

52

The construction of a mass registry for insect species would benefit studies that currently depend on imprecise surrogates, facilitating comparisons across groups with differing morphology. Aggregating data from all insect orders and other arthropods, which are typically studied independently, would advance understanding of mass variation and its evolutionary trajectories across lineages (Ulrich, 2007; Chown \& Gaston, 2010). Museum specimens has been proposed as a resource to assemble mass data for insects without new sampling effort (Gilbert, 2011). However, to assess the quality of the mass data resulting from their analysis, the impact of varying curatorial and preservation methods requires investigation.

60

With over 380,000 described species (Bouchard et al., 2017), Coleoptera is one of the most diverse orders of insects. Occurring in both aquatic and terrestrial environments, it includes some of the largest and smallest insects with its component taxa spanning eight orders of magnitude in mass (Chown \& Gaston, 2010). These factors make Coleoptera an ideal group for developing approaches to support the construction of a mass registry for all insects. The present study targets the Coleoptera of Canada, a fauna of nearly 9,000 species (Brunke et al., 2019), many possessing a DNA barcode record on BOLD (Ratnasingham \& Hebert, 2007). The mass data gathered in this study provide a strong basis for comparison with previous surveys (Chislenko, 1981; Novotny \& Kindlmann, 1996; Ulrich, 2007). As well, because these values derive from specimens with DNA barcodes, it begins to develop the information on mass variation needed to advance both metabarcoding and eDNA analyses (Braukmann et al., 2019).

72

This study details variation in the body mass of 3,161 BIN clusters of Coleoptera based on the analysis of 3,744 museum specimens. It evaluates the impacts of humidity, tissue loss, and curatorial variables on mass. It also examines the extent of variation in mass among taxonomic lineages, work which indicates that phylogenetic constraints are strong enough for the current data to allow mass estimation for most Canadian Coleoptera. Finally, this study considers how best to expand from the current registry that includes records for a few thousand species to one with coverage for all insect species. 
80

81

82

83

84

85

86

87

88

89

90

91

92

93

94

95

96

97

98

99

100

101

102

103

104

105

106

107

108

109

110

111

112

113

114

115

116

117

118

119

\section{Materials \& Methods}

\section{BINs as a species proxy}

DNA barcoding employs sequence variation in a 658 base pair segment of the cytochrome $c$ oxidase subunit I gene (COI) as a basis for specimen identification and species discovery in animals (Hebert et al., 2003). The BIN system clusters these COI sequences into molecular operational taxonomic units (Floyd et al., 2002) that correspond closely with Linnaean species. For example, about $90 \%$ of all species in the well-studied European Coleoptera fauna show perfect correspondence with BINs (Pentinsaari, Hebert \& Mutanen 2014; Hendrich et al., 2015). Divergent BINs associated with the same Linnaean species name often show morphological differences upon closer inspection, while some closely related species share BINs or even identical barcode haplotypes (Pentinsaari, Hebert \& Mutanen 2014; Hendrich et al., 2015). Each $\mathrm{BIN}$ is assigned a unique alphanumeric identifier that serves as a species proxy (Ratnasingham $\&$ Hebert, 2013). Because they provide a taxonomic assignment for undescribed species (Brunke et al. 2019; Brunke et al. 2021), this study employed BINs to structure data collection. While substantial efforts were also made to assign each BIN to a Linnaean species, this was not always possible because of both the lack of taxonomic specialists for some families and difficulties in resolving synonymies and cryptic species. As a result, we employ the BIN count as the best estimator of the number of species examined in this study.

\section{Body mass data}

Specimens were available for 3,161 BINs of Canadian Coleoptera. They represented 1,100 of the 2,008 genera (54.8\%) and 96 of the 111 beetle families (86.5\%) known from Canada (Bousquet et al., 2013). Most were morphologically identified to a genus $(3,156 \mathrm{BINs})$ and many to a species (2,719 BINs to 2,389 recognized species). The specimens were obtained from sampling programs coordinated by the Centre for Biodiversity Genomics (CBG) at the University of Guelph and are stored in its voucher collection. Specimens missing major body segments (head, abdomen) were not weighed. In total, 3,744 specimens were analyzed, meaning a single specimen was weighed for most BINs. However, 2-8 specimens were weighed for 334 BINs, and, for these taxa, a mean mass was calculated. Standard deviation and coefficient of variation were calculated for all BINs represented by at least three specimens in order to explore the extent of mass variation within BINs.

Specimens fell into three main curatorial categories (ethanol, pointed, pinned). Specimens from $70 \%$ ethanol were first air-dried and then weighed repeatedly until the mass measurement stabilized. Specimens on points were unmounted using 70\% ethanol, dried, and weighed. Pinned specimens were weighed on their pin and the pin mass was subtracted. When mass variation 
120 among pins of the size used on a specimen exceeded 12.5\% of its overall weight (Gilbert, 2011), 121 it was unpinned and weighed directly.

122

123

124

125

126

127

128

129

130

131

132

133

134

135

136

137

138

139

140

141

142

143

144

145

146

147

148

149

150

151

152

153

154

155

156

157

158

159

The mass of small specimens ( $\sim 2,800$ representing 2,500 BINs) was quantified to the nearest $0.0001 \mathrm{mg}$ using a high-precision balance (Mettler Toledo ${ }^{\text {TM }}$ XP6U), while the $\sim 950$ larger specimens $(>10 \mathrm{mg})$ were weighed to the nearest $0.1 \mathrm{mg}$ using a less sensitive instrument (Mettler Toledo $\left.{ }^{\mathrm{TM}} \mathrm{MS} 104 \mathrm{~S}\right)$. Up to three significant figures were recorded. The BIN, taxonomic assignment, and mass of each analyzed specimen are provided in a supplementary document (Data S1).

In order to examine the relationship between fresh and dry body mass, 73 specimens of Coleoptera representing a range of body sizes were freshly collected, killed, and weighed within 24 hours. The specimens were then stored dry at room temperature and weighed every 60 days until their mass stabilized, and the final weight was recorded as their dry mass. A linear regression was performed to assess the correlation between fresh and dry mass.

\section{Data description and distribution analyses}

All analyses were performed in $\mathrm{R}$ version 3.6.3 (R Core Team, 2020). Mass values were logtransformed before further analysis, and the interquartile range (IQR) was used as a measure of variance. A two-sided D'Agostino test was employed to evaluate skewness in the data, and an Anscombe-Glynn test to assess kurtosis. One-way ANOVAs using family, subfamily, and generic assignments as variables were used to assess mass variation at different levels in the taxonomic hierarchy using respective groups containing two or more quantified BINs. A nested ANOVA was also used to examine variation partitioning in the 50 families and 449 genera that were nested with two or more subgroups. Because taxonomic groups with low species diversity tend to show less variation in mass (Chown \& Gaston, 2010), a separate analysis was performed to ascertain how variation in mass was partitioned in the most diverse groups of Canadian Coleoptera. In particular, a one-way ANOVA examined 65 genera with mass data for 10 or more BINs, while a nested ANOVA examined the six families with mass data for $>100$ BINs. To quantify the extent of mass that could be partitioned at each taxonomic level, $\omega^{2}$ values were calculated for all ANOVAs.

\section{Pin variation and reproducibility assessment}

A pinned insect is not easily separated from its pin, creating a complexity because the pin can outweigh the specimen. Gilbert (2011) proposed a workaround that involves estimating pin mass from key parameters (material, shape, size) before subtracting this value from the total weight to produce a mass estimate for the insect. Because the CBG employs insect pins from a single supplier, this source of variation was readily assessed. The mean and standard deviation in both

Peer) reviewing PDF | (2021:10:67283:1:0:NEW 23 Dec 2021) 
160

161

162

163

164

165

166

167

168

169

170

171

172

173

174

175

176

177

178

179

180

181

182

183

184

185

186

187

188

189

190

191

192

193

194

195

196

197

198

199

diameter and mass was determined for 100 pins of each size. Because there was no overlap in diameter among different pin sizes, the size associated with each specimen could be determined, allowing its mass to be subtracted.

The consistency in determinations of pin size and of body mass was assessed by comparing mass values for 112 specimens weighed in 2014 and again in 2018. The congruence in net mass values was examined using a paired-sample t-test. To evaluate short-term variation in mass, 18 specimens were weighed daily on four consecutive days when variation in humidity was pronounced.

Since the specimens studied had been DNA barcoded before weighing, many lacked a leg or the part of it (e.g., tarsus) that was used for DNA extraction. As part of a set of pilot tests performed before commencing the weighing of specimens on a large scale, 50 specimens were examined to determine the reduction in mass caused by the loss of a leg.

\section{Results}

\section{Mass variation in Canadian Coleoptera}

Measurements of the 3,744 beetles representing 3,161 BINs revealed their mass varied by more than five orders of magnitude $(0.0024-797 \mathrm{mg})$ (Fig 1). Among BINs with a species assignment, Ptiliola kunzei (Ptiliidae, BOLD:ACI8875) and Ptiliolum fuscum (Ptiliidae, BOLD:AAM7677) possessed the lowest mass $(0.0056 \mathrm{mg})$. However, six BINs in the same subfamily (Ptiliinae) weighed less, and a specimen identified to the genus Nanosella (BOLD:ADH5266) had the lowest mass (0.0024 mg). The largest species was Hydrophilus triangularis (Hydrophilidae, BOLD:AAQ2470) at $797 \mathrm{mg}$. The median mass of all species was $\sim 1.3 \mathrm{mg}$, represented in the data by species such as Bembidion nitidum (Carabidae, BOLD:AAD2752) and Dichelotarsus piniphilus (Cantharidae, BOLD:AAH0933). Considering all BINs, the mass distribution approximated a lognormal distribution with strong kurtosis $\left(z=-7.39, p=1.49^{-13}\right)$ but insignificant skew $(z=1.96, p=0.051)$. The coefficient of variation for the 196 BINs with a minimum sample size of three specimens ranged from 0.02 to 0.975 (Data S1). The fresh and dry body mass of 73 beetle specimens freshly collected from the field showed a strong linear relationship $\left(\mathrm{R}^{2}=0.97\right)$, with dry mass being approximately $49 \%$ of the fresh mass.

Much of the variation in mass among species was linked to their higher taxonomic assignments (family, subfamily, genus) (Table 1. a-c). In fact, $\omega^{2}$ values indicated that $90 \%$ of the mass variation could be explained by higher taxonomic placement with $55 \%$ of the variation at the family level, $20 \%$ at the subfamily level, and $15 \%$ at the genus level. Because of these relationships, variation in mass among congeneric species was typically limited (Fig 2). Considering all 518 genera where two or more BINs were examined, the variance, measured by 
200 IQR, had a median of $0.163 \log _{10}(\mathrm{mg})$, which is a 1.4 -fold difference and translates to $+/-20 \%$ 201 divergence from the median for the genus. Cases of extreme variation where the larger members 202 of the genus were as twice as massive as the median (IQR $>0.6$ ) were only observed in nine of 203 the 518 genera, including Anotylus (Staphylinidae), Dyschirius (Carabidae) and Ilybius 204 (Dytiscidae) (Data S1). Genera with ten or more measured BINs showing low IQR $(<0.15)$ 205 included e.g. Acrotrichis (Ptiliidae), Anaspis (Scraptiidae), and Paria (Chrysomelidae) (Data 206 S1).

207

Diameter measurements allowed the discrimination of each pin size as differences among pins of a particular size were an order of magnitude $( \pm 0.005 \mathrm{~mm})$ less than the diameter difference $(0.05$ $\mathrm{mm})$ between adjacent pin sizes. Pins of one size did vary in mass $( \pm 0.2-0.9 \mathrm{mg})$ with this variation increasing with larger pins, but it usually represented a small component of the overall

214

215

216 mass. In the few cases where variation in pin mass represented $>12.5 \%$ of the total weight, the specimen was unmounted and weighed directly.

High humidity slowed analysis as the balances required longer to stabilize, but changes in mass linked to variation in temperature and humidity were small. For example, the mean standard error based on measurements of 18 specimens weighed every 24 hours over four days was $1-2 \%$ of their mean (Data S1). Comparison of specimen weights between 2014 and 2018 further indicated that differences between paired measurements were within $\pm 3 \%$ of their average in 109 of 112 cases while the others were within $\pm 5 \%$. A paired t-test demonstrated that mean mass increased by $0.3 \%(t=2.0657, \mathrm{df}=111, p=0.02)$ over the interval, likely reflecting higher humidity when the second measurements were made.

225

226

227 the loss of an appendage had a small impact on mass. For example, a leg typically represented 1$2 \%$ of the specimen's mass, while the tibia plus tarsus were around $0.5 \%$. The loss of a major body segment (head, abdomen) had much larger impacts as they comprised from $12-50 \%$ respectively of the total mass.

233

\section{Discussion}

Because of its strong association with crucial biological traits, mass data is valuable in many ecological and evolutionary contexts (Niven \& Scharlemann, 2005; Beukeboom, 2018). By assembling mass data for 3,161 Coleoptera BINs, this study confirms that museum specimens are a valuable resource for constructing a mass registry. It further demonstrates that factors such as the loss of an appendage, variation in humidity, specimen age, and curatorial practices have small impacts on these measurements. 
240

241

242

243

244

245

246

247

248

249

250

251

252

253

254

255

256

257

258

259

260

261

262

263

264

265

266

267

268

269

270

271

272

273

274

275

276

277

278

279

This study further demonstrates that mass variation among beetles has strong phylogenetic constraints with much of the variation residing at the family, subfamily, and generic levels. As a consequence, the analysis of a single or a few individuals of a species provides a good estimate of its mass. Prior studies have demonstrated that adult body size can be impacted by diverse environmental factors and by sexual dimorphism, and that the extent of such variation differs among species (Emlen \& Allen, 2003; Kawano, 2006; Chown \& Gaston, 2010; Tseng et al., 2018). For example, many species of Scarabaeidae and Lucanidae show both prominent sexual dimorphism and extensive size variation within sexes (Kawano, 2006). As extreme variability of adult body size due to variation in the quantity and quality of larval food has also been well documented in e.g. Cerambycidae (Svacha \& Lawrence, 2014), it was not surprising that 15 of the 30 BINs with the highest coefficients of variation belonged to this family. These impacts can even shift the relationship between morphometric measurements (e.g., body length) and biomass (Gouws, Gaston \& Chown, 2011). The inclusion of multiple representatives of both sexes in mass databases is warranted in such taxa to provide a more accurate estimate of mean body mass, to account for this variation in analyses, and to improve the accuracy of body size prediction of congenerics. However, given the millions of insect species, investigating such impacts on a species-by-species basis is not feasible, and it is unnecessary in most contexts because they generally cause only minor modulations in body mass as $>90 \%$ of variation resides at higher taxonomic levels (Chown \& Gaston, 2010). While a single data point per species does not provide a detailed characterization of its mass, the collective data for a genus or subfamily are a meaningful indicator of body size in the lineage.

Because the present analysis only considered adult body mass, these data will be of lesser value for samples consisting largely of larvae as their mass increases by orders of magnitude during development (e.g., Nijhout, Davidowitz \& Roff, 2006). In fact, mature larvae of holometabolous insects frequently outweigh adults (Waters \& Harrison, 2012). Adult body mass is more useful in many modeling situations (e.g., female fecundity typically shows a positive correlation with body mass (Taylor, Anderson \& Peckarsky, 1998; Beukeboom, 2018)).

Importantly, mass estimates derived from generic assignments are similar in accuracy to those resulting from the standard approach to mass estimation: the use of a power equation to estimate mass from body length (Rogers, Hinds \& Buschbom, 1976). While our data set is larger and spans a greater range of mass, our residual SE (0.62) was less than that resulting from the use of a power equation (Table 1.c). In fact, even when our analysis targeted genera with the most variation in mass among their component species, the residual SE (0.69) was similar to that (0.66) reported with the use of a power equation (Rogers, Hinds \& Buschbom, 1976) (Table 1.d). While this residual translates into an average two-fold difference in mass from the predicted value, it indicates that a generic assignment can generate mass estimates with a precision similar to those based on estimates from direct length measurements. In short, mass values for a few

Peer] reviewing PDF | (2021:10:67283:1:0:NEW 23 Dec 2021) 
280

281

282

283

284

285

286

287

288

289

290

291

292

293

294

295

296

297

298

299

300

301

302

303

304

305

306

307

308

309

310

311

312

313

314

315

316

317

318

319

species in each genus allow the estimation of mass for congeneric taxa. Although our results only document this fact for Coleoptera, similar relationships undoubtedly extend to other groups, as strong phylogenetic signal in body size occurs in many arthropod lineages (Rainford, Hofreiter \& Mayhew, 2016). Understanding the extent of phylogenetic constraint in arthropods could greatly speed the development of a functional mass registry by allowing analysis to focus on groups where size variation is most pronounced and to use proxy measures in those where it is not.

By delivering information on body mass for about $0.2 \%$ of all described insect species, the present study indicates that it is feasible to construct a mass registry for all insects. Furthermore, it reveals shortcuts to develop this registry. Specifically, the strong phylogenetic constraints on mass indicate that early efforts should focus on gaining coverage for higher taxonomic categories - every insect family and subfamily. Work should then extend to every genus and in time to every species. Because this effort will generate a substantial volume of data, it needs a home and the BOLD platform (Ratnasingham \& Hebert, 2007) is well-suited to meet this need. Although specimens with mass data need not possess barcode records, the inclusion of sequence information will maximize the utility of these records for metabarcoding and eDNA analysis: As larger specimens tend to release more DNA, information on body mass is crucial for estimating abundances from bulk samples, although the impacts of DNA extraction and PCR amplification protocols must also be considered (Elbrecht, Peinert \& Leese, 2017; Deagle et al., 2018).

Moreover, the barcode records will ensure that specimens in the mass registry are properly identified, one of the key problems confronting any large-scale repository of biological collaterals. To demonstrate its capacity, the current records are deposited in a dataset on BOLD (DS-MASSCOL; dx.doi.org/10.5883/DS-MASSCOL) that couples barcode records with mass information on each specimen examined in this study. Because DS-MASSCOL is a dynamic dataset where BIN assignments may shift and where specimens that currently lack a genus or species assignment may gain one, a supplemental file (Data S2) has been provided as a snapshot at the time of submission.

\section{Conclusions}

Aside from its value on providing a basis for extending understanding of the evolution of body mass, comprehensive body mass data on insect species is needed for ecological modeling. By confirming that variable curatorial and preservation practices have little impact on body mass, the present study establishes that museum specimens provide a resource for the rapid assembly of mass data. Employing this approach, the present study assembled mass data for 3,161 species of Coleoptera, nearly $1 \%$ of all known species in this order. Moreover, because of the strong phylogenetic constraints on body size, the current records enable accurate mass estimation (+/$20 \%$ ) for nearly all Canadian beetles. The extension of this approach to other arthropod groups and other geographic regions would facilitate the assembly of a mass registry for all insects. 
320 Incorporation of the resultant mass value for each BIN into the parameters on BOLD will ensure

321

322

323

324

325

326

327

328

329

330

331

332

333

334

335

336

337

338

339

340

341

342

343

344

345

346

347

348

349

350

351

352

353

354

355

356

357

358

easy access to these data.

\section{References}

Bouchard P, Smith ABT, Douglas H, Gimmel ML, Brunke AJ, Kanda K. 2017. Biodiversity of Coleoptera. In: Foottit RG, Adler PH, eds. Insect Biodiversity: Science and Society. Chichester: John Wiley \& Sons, Ltd, 337-417.

Bousquet, Y, Bouchard, P, Davies, AE, Sikes, DS. 2013. Checklist of beetles (Coleoptera) of Canada and Alaska. Second edition. ZooKeys 360: 1-44 DOI: 10.3897/zookeys.360.4742

Braukmann TWA, Ivanova NV, Prosser SWJ, Elbrecht V, Steinke D, Ratnasingham S, deWaard JR, Sones JE, Zakharov E V., Hebert PDN. 2019. Metabarcoding a diverse arthropod mock community. Molecular Ecology Resources 19: 711-727 DOI: 10.1111/1755-0998.13008

Braun M, Simon E, Fábián I, Tóthmérész B. 2009. The effects of ethylene glycol and ethanol on the body mass and elemental composition of insects collected with pitfall traps. Chemosphere 77: 1447-1452 DOI: 10.1016/j.chemosphere.2009.08.051

Beukeboom LW. 2018. Size matters in insects - an introduction. Entomologia Experimentalis et Applicata 166:2-3 DOI: 10.1111/EEA.12646

Brunke AJ, Bouchard P, Douglas HB, Pentinsaari M. 2019. Coleoptera of Canada. ZooKeys 819: 361-376 DOI: 10.3897/zookeys.819.24724

Brunke AJ, Pentinsaari M, Klimaszewski J. 2021. Integrative taxonomy of Nearctic and Palaearctic Aleocharinae: new species, synonymies, and records (Coleoptera, Staphylinidae).

ZooKeys 1041: 27-99 DOI: 10.3897/zookeys.1041.64460

Chislenko LL. 1981. Structure of Fauna and Flora in Connection with Organism Size. Moscow: Moscow University Press.

Chown SL, Gaston KJ (2010) Body size variation in insects: a macroecological perspective. Biological Reviews 8: 139-169 DOI: 10.1111/j.1469-185X.2009.00097.x

Deagle BE, Clarke LJ, Kitchener JA, Polanowski AM, Davidson AT. 2018. Genetic monitoring of open ocean biodiversity: An evaluation of DNA metabarcoding for processing continuous 
359 plankton recorder samples. Molecular Ecology Resources 18: 391-406 DOI: 10.1111/1755$360 \quad 0998.12740$.

361

362

Dunning JB. 2008. CRC Handbook of avian body masses. Georgia: CRC Press.

363

364

Elbrecht V, Peinert B, Leese F. 2017. Sorting things out: Assessing effects of unequal specimen

365 biomass on DNA metabarcoding. Ecology and Evolution 7: 6918-6926 DOI:

366 10.1002/ECE3.3192.

367

368

Emlen DJ, Allen CE. 2003. Genotype to phenotype: physiological control of trait size and

369

scaling in insects. Integrative and Comparative Biology 43: 617-634 DOI: 10.1093/icb/43.5.617

370

371

Floyd R, Abebe E, Papert A, Blaxter M (2002) Molecular barcodes for soil nematode

372

identification. Molecular Ecology 11: 839-850 DOI: 10.1046/j.1365-294X.2002.01485.x

373

374

Froese R, Pauly D. 2021. FishBase (version 06/2021). Available at http://www.fishbase.org

375 (accessed 29 October 2021).

376

377

Gilbert JDJ. 2011. Insect dry weight: shortcut to a difficult quantity using museum specimens.

378

Florida Entomologist 94: 964-970 DOI: 10.1653/024.094.0433

379

380

Gouws EJ, Gaston KJ, Chown SL. 2011. Intraspecific body size frequency distributions of

381 insects. PLoS One 6: e16606 DOI: 10.1371/journal.pone.0016606

382

383

Gowing G, Recher HF. 1984. Length-weight relationships for invertebrates from forests in

384 south-eastern New South Wales. Australian Journal of Ecology 9: 5-8 DOI: 10.1111/j.1442-

385 9993.1984.tb01612.x

386

387

388

Greve ME, Hager J, Weisser WW, Schall P, Gossner MM, Feldhaar H. 2018. Effect of forest 389

390 management on temperate ant communities. Ecosphere 9: e02303 DOI: 10.1002/ecs2.2303

391

Hebert PDN, Cywinska A, Ball SL, deWaard JR. 2003. Biological identifications through DNA barcodes. Proceedings of the Royal Society of London. Series B: Biological Sciences 270: 313-

392 321 DOI: $10.1098 / \mathrm{rspb} .2002 .2218$

393

394

Hendrich L, Morinière J, Haszprunar G, Hebert PDN, Hausmann A, Köhler F, Balke M. 2015. A 395 comprehensive DNA barcode database for Central European beetles with a focus on Germany: 396 adding more than 3,500 identified species to BOLD. Molecular Ecology Resources 15: 795-818 397 DOI: $10.1111 / 1755-0998.12354$ 
399 Johnston TA, Cunjak RA. 1999. Dry mass-length relationships for benthic insects: a review with 400 new data from Catamaran Brook, New Brunswick, Canada. Freshwater Biology 41: 653-674

401 DOI: $10.1046 / j .1365-2427.1999 .00400 . x$

402

403

404

405

406

407

408

409

410

411

412

413

414

415

416

417

418

419

420

421

422

423

424

425

426

427

428

429

430

431

432

433

434

435

436

437

438

Jones KE, Bielby J, Cardillo M, Fritz SA, O'Dell J, Orme CDL, et al. (2009) PanTHERIA: a species-level database of life history, ecology, and geography of extant and recently extinct mammals. Ecology 90: 2648-2648 DOI: 10.1890/08-1494.1

Kawano K. 2006. Sexual Dimorphism and the making of oversized male characters in beetles (Coleoptera). Annals of the Entomological Society of America 99: 327-341 DOI: 10.1603/00138746(2006)099[0327:SDATMO]2.0.CO;2

Knapp M. 2012. Preservative fluid and storage conditions alter body mass estimation in a terrestrial insect. Entomologia Experimentalis et Applicata 143: 185-190 DOI: 10.1111/j.15707458.2012.01247.x

Nijhout HF, Davidowitz G, Roff DA. 2006. A quantitative analysis of the mechanism that controls body size in Manduca sexta. Journal of Biology 5:1-15 DOI:

10.1186/JBIOL43/FIGURES/15.

Niven JE, Scharlemann JPW. 2005. Do insect metabolic rates at rest and during flight scale with body mass? Biology Letters 1: 346-349 DOI: 10.1098/RSBL.2005.0311

Novotny V, Kindlmann P. 1996. Distribution of body sizes in arthropod taxa and communities. Oikos 75: 75-82 DOI: 10.2307/3546323

Pentinsaari M, Hebert PDN, Mutanen M. 2014. Barcoding beetles: a regional survey of 1872 species reveals high identification success and unusually deep interspecific divergences. PLoS One 9: e108651 DOI: 10.1371/journal.pone.0108651

Pentinsaari M, Anderson R, Borowiec L, Bouchard P, Brunke A, Douglas H, Smith ABT, Hebert PDN. 2019. DNA barcodes reveal 63 overlooked species of Canadian beetles (Insecta, Coleoptera). ZooKeys 894: 53-150 DOI: 10.3897/zookeys.894.37862

Peters RH. 1986. The ecological implications of body size. Cambridge: Cambridge University Press.

R Core Team. 2020. R: A language and environment for statistical computing. Vienna: $\mathrm{R}$ Foundation for Statistical Computing.

Peer) reviewing PDF | (2021:10:67283:1:0:NEW 23 Dec 2021) 
439 Rainford JL, Hofreiter M, Mayhew PJ. 2016. Phylogenetic analyses suggest that diversification 440 and body size evolution are independent in insects. BMC Evolutionary Biology 16: 8-25 DOI:

$441 \quad 10.1186 / \mathrm{s} 12862-015-0570-3$

442

443 Ratnasingham S, Hebert PDN. 2007. BOLD: The Barcode of Life Data System

444 (www.barcodinglife.org). Molecular Ecology Notes 7: 355-364 DOI: 10.1111/j.1471-

$445 \quad 8286.2007 .01678 . x$

446

447

448

449

450

451

452

453

454

455

456

457

458

459

460

461

462

463

464

465

466

467

468

469

470

471

472

473

474

475

476

477

478
Ratnasingham S, Hebert PDN. 2013. A DNA-based registry for all animal species: The Barcode Index Number (BIN) System. PLoS One 8: e66213 DOI: 10.1371/journal.pone.0066213

Richard M, Tallamy DW, Mitchell AB. 2019. Introduced plants reduce species interactions. Biological Invasions 21: 983-992 DOI: 10.1007/s10530-018-1876-Z

Rogers LE, Hinds WT, Buschbom RL. 1976. A general weight versus length relationship for insects. Annals of the Entomological Society of America 69: 387-389 DOI:

10.1093/aesa/69.2.387

Smith FA, Payne JL, Heim NA, Balk MA, Finnegan S, Kowalewski M, Lyons SK, McClain CR, McShea DW, Novack-Gottshall PM, Anich PS, Wang SC. 2016. Body size evolution across the Geozoic. Annual Review of Earth and Planetary Sciences 44: 523-553 DOI: 10.1146/annurevearth-060115-012147

Svacha P, Lawrence JF. 2014. Cerambycidae Latreille, 1802. In: Leschen RAB, Beutel RG, eds. Handbook of Zoology. Coleoptera, beetles. Volume 3: morphology and systematics

(Phytophaga). Berlin: De Gruyter, 77-177.

Taylor BW, Anderson CR, Peckarsky BL. 1998. Effects of size at metamorphosis on stonefly fecundity, longevity, and reproductive success. Oecologia 114: 494-502.

Tseng M, Kuar KM, Pari SS, Sarai K, Chan D, Yao CH, Porto P, Toor A, Toor HS, Fograscher K. 2018. Decreases in beetle body size linked to climate change and warming temperatures.

Journal of Animal Ecology 87: 647-659 DOI: 10.1111/1365-2656.12789

Ulrich W. 2007. Body weight distributions of central European Coleoptera. European Journal of Entomology 104: 769-776 DOI: 10.14411/eje.2007.098

Waters JS, Harrison JF. 2012. Insect metabolic rates. In: Sibly RM, Brown JH, Kodric-Brown A, eds. Metabolic ecology: a scaling approach. Chichester: John Wiley \& Sons, Ltd, 198-211.

Peer) reviewing PDF | (2021:10:67283:1:0:NEW 23 Dec 2021) 


\section{Figure 1}

Distribution of the log-transformed body masses for 3,161 BINs of Canadian Coleoptera.

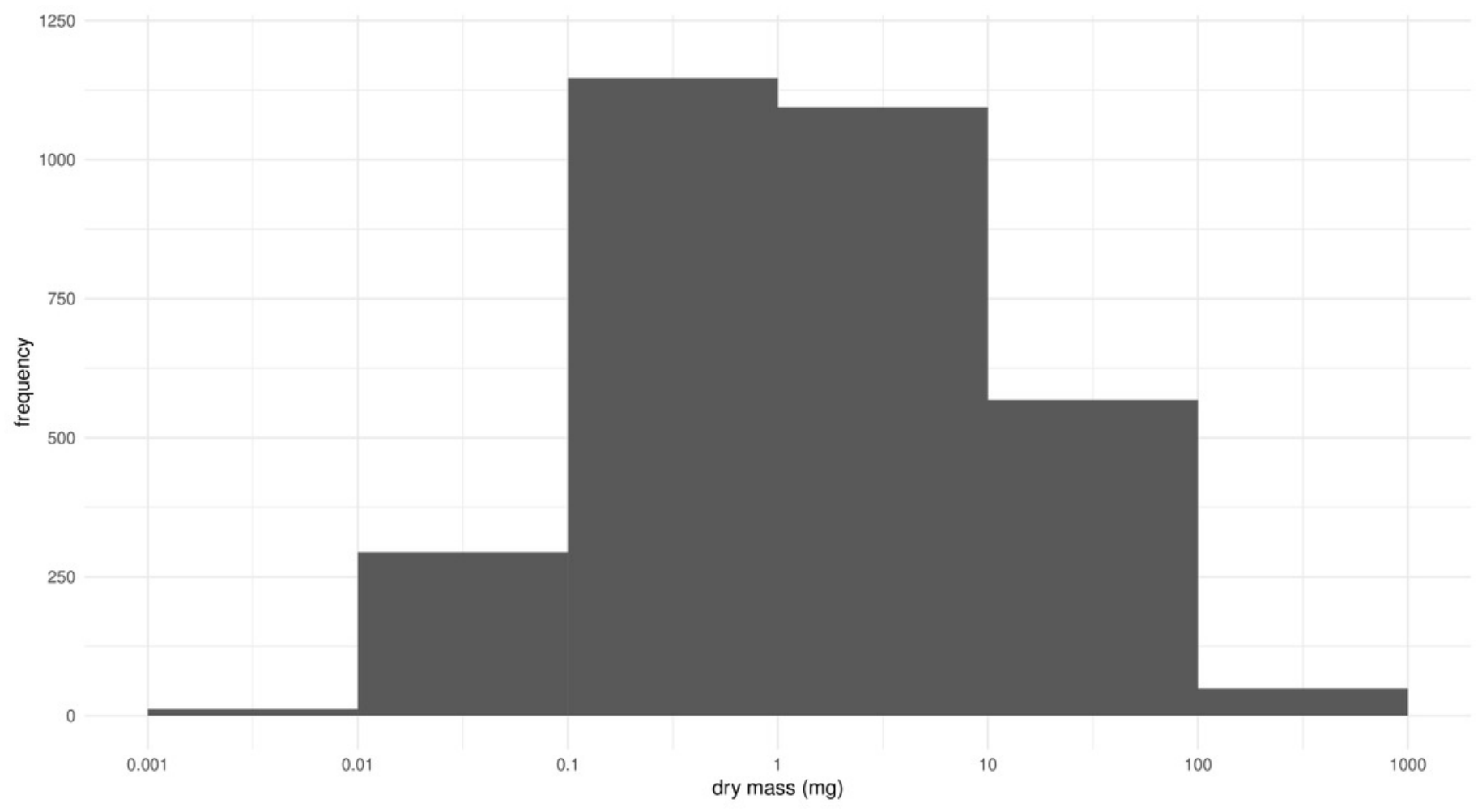




\section{Figure 2}

Distribution of the variance in body mass for Coleoptera genera.

Interquartile range measures the difference between the upper and lower quartiles and can be converted to fold-difference or used to estimate the typical deviation from the median (e.g., IQR $0.2=1.6$-fold difference between quartiles $\approx+/-23 \%$ from median; IQR $0.4=2.5$ fold difference between quartiles $\approx+/-57 \%$ from median).

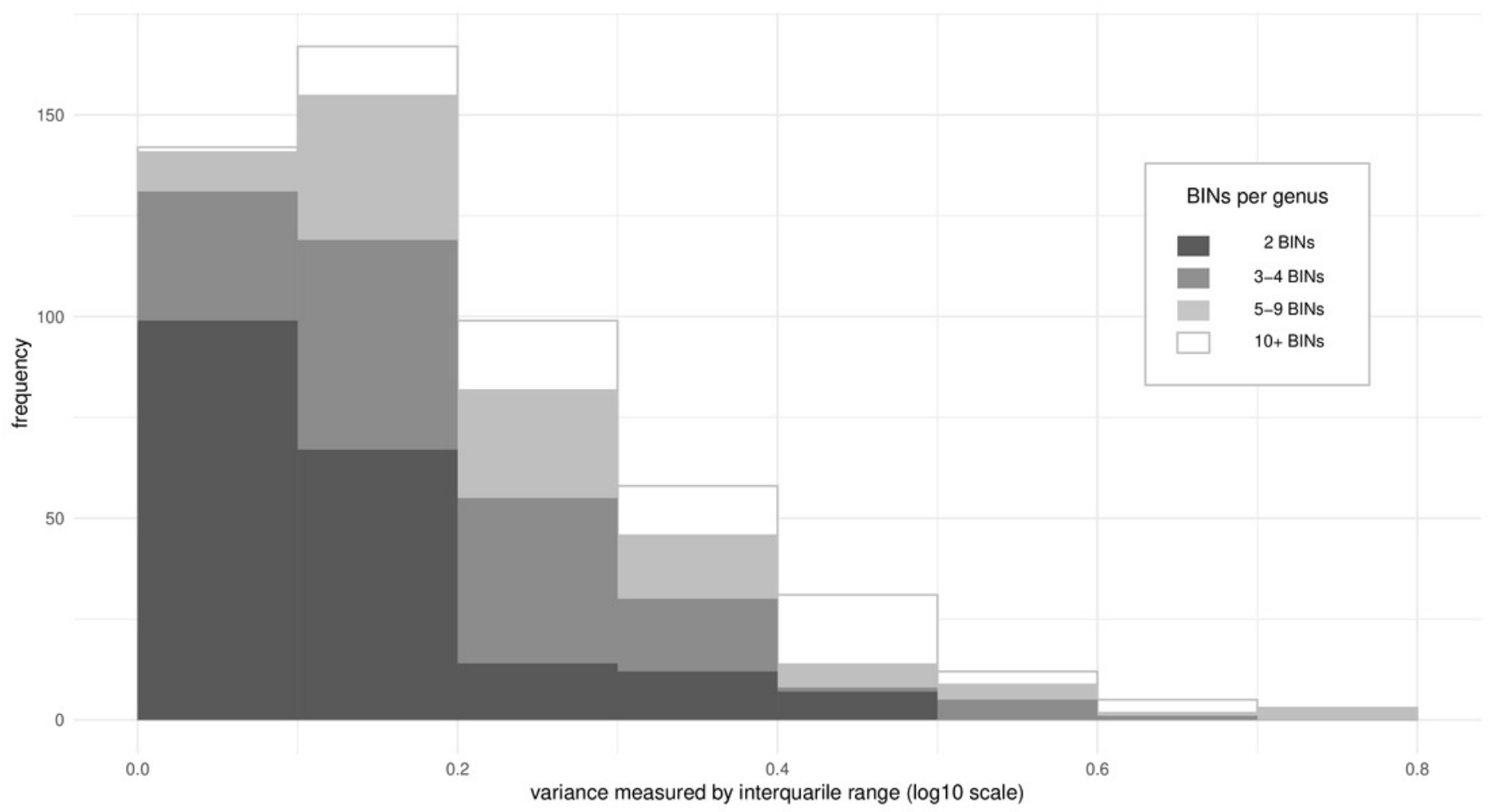


Table $\mathbf{1}$ (on next page)

Output of one-way and nested analyses of variance. 
1 Table 1. Output of one-way and nested analyses of variance.

\begin{tabular}{|c|c|c|c|c|c|c|c|}
\hline Analysis & Factor & D.f. & Sum Sq. & Mean Sq. & $F$ & $p$ & $\omega^{2}$ \\
\hline \multirow{2}{*}{$\begin{array}{l}\text { a) One-way: } \\
\text { family }\end{array}$} & Family & 78 & 7644 & 98.0 & 51.6 & $<2.2^{-16}$ & 0.56 \\
\hline & Residual & 3068 & 5821 & 1.9 & & & \\
\hline \multirow{2}{*}{$\begin{array}{l}\text { b) One-way: } \\
\text { subfamily }\end{array}$} & Subfamily & 183 & 9412 & 51.4 & 46.0 & $<2.2^{-16}$ & 0.74 \\
\hline & Residual & 2749 & 3075 & 1.12 & & & \\
\hline \multirow{2}{*}{$\begin{array}{l}\text { c) One way: } \\
\text { genus }\end{array}$} & Genus & 518 & 9934 & 19.2 & 50.0 & $<2.2^{-16}$ & 0.91 \\
\hline & Residual & 2059 & 790 & 0.38 & & & \\
\hline \multirow{2}{*}{$\begin{array}{l}\text { d) One way: } \\
\text { genera with } n \geq \\
10\end{array}$} & Genus & 64 & 3630 & 56.7 & 118.2 & $<2.2^{-16}$ & 0.88 \\
\hline & Residual & 957 & 459 & 0.48 & & & \\
\hline \multirow{3}{*}{$\begin{array}{l}\text { e) Nested: family } \\
\text { and genus levels }\end{array}$} & Family & 49 & 6185 & 126.2 & 329.6 & $<2.2^{-16}$ & 0.59 \\
\hline & Family/Genus & 448 & 3561 & 7.95 & 20.8 & $<2.2^{-16}$ & 0.32 \\
\hline & Residuals & 2013 & 771 & 0.38 & & & \\
\hline \multirow{3}{*}{$\begin{array}{l}\text { f) Nested: families } \\
\text { with } n \geq 100\end{array}$} & Family & 5 & 3046 & 609.2 & 1407 & $<2.2^{-16}$ & 0.51 \\
\hline & Family/Genus & 269 & 2383 & 8.9 & 20.5 & $<2.2^{-16}$ & 0.38 \\
\hline & Residuals & 1174 & 508.4 & 0.4 & & & \\
\hline
\end{tabular}

